\title{
A Linder Hypothesis for Foreign Direct Investment*
}

\author{
Pablo Fajgelbaum \\ U.C.L.A.
}

\author{
Gene M. Grossman \\ Princeton University
}

\author{
Elhanan Helpman \\ Harvard University and CIFAR
}

October 2011

\begin{abstract}
We combine a product-quality view of the Linder hypothesis with a proximity-concentration view of firms' decision about how to serve foreign markets. Our model features non-homothetic preferences for quality and monopolistic competition. As a result, specialization is purely demand-driven and the decision to serve foreign countries via exports or FDI depends on differences in income across countries. We characterize the joint pattern of trade and FDI in a world with multiple countries that differ in income and size. We find that FDI is more likely to occur between countries with similar per capita income levels, suggesting a Linder effect for FDI. The theory sheds light on some salient features that have been found in the data; in particular, we identify circumstances for the emergence of North-North and South-South multinational enterprises.
\end{abstract}

Keywords: monopolistic competition, vertical specialization, product quality, nested logit, trade, FDI, multinational corporations

JEL Classification: F12, F23

\footnotetext{
${ }^{*}$ Grossman and Helpman thank the National Science Foundation and Fajgelbaum thanks the International Economics Section at Princeton University for financial support. Part of the work on this paper was carried out while Grossman was a Visiting Research Fellow in the Development Economics Vice Presidency at the World Bank. He thanks the World Bank for support and the Trade and Integration Team (DECTI) for its hospitality. Any opinions, findings, and conclusions or recommendations expressed in this paper are those of the authors and do not necessarily reflect the views of the National Science Foundation, the World Bank Group, or any other organization.
} 


\section{Introduction}

The Linder hypothesis seeks to explain patterns of international trade. Linder (1961) conjectured that robust local demands for a good induce investments in productive capacity, which in turn give rise to exports. Due to such "home-market effects" (to use the term coined by Krugman, 1980), countries will trade intensively with others that share similar consumption patterns. Moreover, to the extent that demands for many goods are non-homothetic, intensive trade between countries that have similar demand structures implies intensive trade between countries that have similar levels of per capita income. Accordingly, Linder offered an early explanation for the high volumes of trade between and among the high-income countries. ${ }^{1}$

More recently, Hallak (2010) and Fajgelbaum et al. (2011) have pursued a "product-quality view" of the Linder hypothesis. This view builds on evidence presented by Schott (2004) and Hummels and Klenow (2005) that richer countries tend to export goods of higher unit value within narrowly defined product categories and evidence from Hallak (2006) that exporters disproportionately direct their higher-priced goods to higher-income markets. Also, Bils and Klenow (2001) highlighted a strong positive correlation between household income and the average price paid by the household for goods within product groups. If high unit values are an indication of high quality, then together this evidence suggests a world in which countries with more high-income consumers demand more of the higher quality goods and also specialize in their production. ${ }^{2}$ Fajgelbaum et al. (2011) incorporate trade costs into a model in which non-homothetic preferences imply that higher-income groups consume goods of higher average quality to generate predictions about the trade pattern. Their predictions mirror those of the Linder hypothesis. Hallak (2010) presents evidence in keeping with such predictions using industry-level data.

So far, the product-quality approach to the Linder hypothesis, and work related to the Linder hypothesis more generally, has only been concerned with explaining trade patterns. Yet the key forces in these approaches might also be important for understanding global patterns of foreign direct investment (FDI). A prominent view of the determinants of FDI is that firms' decisions about how to serve foreign markets reflect a "proximity-concentration tradeoff" (Markusen, 1984). In the presence of trading costs, firms are more likely to serve foreign markets from local production facilities when those markets are large. ${ }^{3}$ A product-quality view of the Linder hypothesis suggests that market size will vary with per capita income and product quality, which may therefore influence

\footnotetext{
${ }^{1}$ Numerous papers have found evidence consistent with the Linder hypothesis, e.g. Thursby and Thursby (1989), Bergstrand (1990), Francois and Kaplan (1996) and Fieler (2011). Markusen (1986) is an early example of a formal theory featuring a form of the Linder effect. In his model, rich capital-abundant countries trade intensely among themselves due to increasing returns to scale and a high income-elasticity of demand for the capital intensive good.

${ }^{2}$ Using a methodology that does not rely on unit values as the sole proxy for product quality, Hallak and Schott (2011) also show that richer countries specialize in the production of higher quality goods.

${ }^{3}$ By many accounts, market size - along with trading costs and scale economies - is an important determinant of FDI flows and sales by foreign subsidiaries. See, for example, Brainard (1997), Carr et al. (2001), Markusen and Maskus (2002), Helpman et al. (2004) and Yeaple (2009).
} 
the circumstances under which foreign investment is a more likely outcome than international trade.

In this paper we combine a quality view of the Linder hypothesis and a proximity-versusconcentration view of firms' decision about how to serve foreign markets. We extend the model in Fajgelbaum et al. (2011) to allow for affiliate sales by multinational corporations. As in our earlier paper, consumers make discrete choices of a horizontally and vertically differentiated product. Each consumer has an idiosyncratic evaluation of each of the available varieties of the differentiated product and some positive fraction of consumers at any income level purchases every available brand. However, preferences are such that the fraction of consumers that opts for one of the higher quality varieties rises with income. It follows that, in equal-sized countries with different distributions of income, the aggregate demand for the set of higher quality varieties will be greater in the market with more of the high-income consumers. The presence of trading costs generates a home-market effect that governs the pattern of specialization. In this setting, we add an option to serve foreign markets via either exports or subsidiary sales. Firms face a constant per unit cost of exporting and a fixed cost of setting up a foreign production facility, so their choice about how to serve a given market features the familiar proximity-concentration tradeoff. To study the patterns of trade and FDI that can arise, we need an environment with multiple countries at each level of income. We adopt the simplest such setting, which has two countries in the North and two in the South.

We are interested in understanding the circumstances under which firms in a country will choose to serve some foreign markets by exports and others by subsidiary sales. We find that a systematic bias characterizes the possible equilibrium configurations. When the pairs of countries in each region are symmetric, North-to-North FDI or South-to-South FDI must occur in any equilibrium that features multinational investment. Moreover, in our baseline case with equal numbers of consumers in all countries, if the income distribution in each Northern country dominates that in each Southern country, multinationals from the North specialize in producing high-quality products while multinationals from the South specialize in producing low-quality products. This result reflects the combined forces of the home-market effect and the proximity-concentration tradeoff. The former implies that countries tend to specialize in goods with large domestic markets. With non-homothetic preferences, these are likely to be higher quality goods in countries with many high-income consumers and lower quality goods in countries with many low-income consumers. The latter implies that firms are more likely to serve foreign markets via sales of foreign affiliates when the destination market is larger. Together, these forces imply that firms may serve destinations that have a similar demand composition to their home market via FDI and destinations that have a different demand composition from their home market via export sales. If demand composition comports with the level and distribution of income, then FDI flows may be especially intense among countries that are at a similar stage of development.

In short, the combination of a quality view of the Linder hypothesis and a proximity-versusconcentration view of firms' decision about how to serve foreign markets delivers a Linder hypothesis for FDI. This prediction finds support in the evidence presented by Brainard (1997). She has 
documented that the share of foreign affiliate sales in total sales by U.S. firms falls with the difference in per capita income between the destination market and that in the United States. In other words, the response of multinational sales to income gaps is more pronounced than that for export sales. ${ }^{4}$ In the next section, we provide some additional evidence on the pattern of FDI and the pattern of subsidiary sales. Using data for a broad sample of countries, we show that both the volume of subsidiary sales and the stock of FDI originating in some country and destined for another are negatively related to the difference in per capita income between the pair, after controlling for fixed effects in the origin and destination countries and the geographic distance between them. Our model might also help us to understand the recent rise in South-to-South FDI. ${ }^{5}$ For example, the Boston Consulting Group (2006) has reported that 28 of the largest 100 Southern multinationals have been motivated to invest abroad in order to "tak[e] their established home-market product lines and brands to global markets." These firms, which are concentrated in consumer durables such as electronics and household appliances, produce goods for which arguably there are substantial quality differences between output in the North and the South, and, with their lower unit values, they can target a clientele that is not too different from that in their native market.

A vast literature before us has studied the determinants of foreign direct investment. What distinguishes our theory is its emphasis on explaining a bias in FDI towards countries at a similar stage of development. Having more than one product for which FDI may occur as well as multiple countries is critical for this result: FDI turns out to be more likely across similar-income countries because these countries endogenously specialize in similar-quality products. A literature on "vertical" FDI, emanating from Helpman (1984), studies firms' decision to break down stages of production that differ in factor intensity across locations that differ in factor prices. Naturally, this strand is ill-suited to generate the equilibrium bias in FDI that we find. On the other hand, Markusen and Venables (2000) extend the Helpman and Krugman (1985) set-up with trade costs to allow for a proximity-concentration tradeoff. Theirs is a Hecksher-Ohlin model with two countries, where increasing returns to scale and FDI are allowed in only one industry. Their theory predicts that FDI is more likely to arise the more similar are the factor endowments of the two countries, but they are unable to distinguish between regional or cross-regional FDI. Finally, recent multicountry Ricardian models that feature the proximity-concentration tradeoff, such as Helpman et al. (2004) and Ramondo and Rodriguez-Clare (2009), are able to generate regional FDI, but present no systematic bias in favor of North-to-North or South-to-South flows or endogenous specialization in different products. In these environments, FDI predominantly flows from countries that host more productive firms to countries that have relatively larger markets. ${ }^{6}$

The remainder of the paper is organized as follows. In the next section we present some simple, motivating evidence. We display the average income of the destination country for FDI and for

\footnotetext{
${ }^{4}$ Carr et al. (2001) show that convergence in GDP between the United States and any host country tends to increase affiliate sales in both directions.

${ }^{5}$ Whereas only $15 \%$ of foreign investment flows to developing countries emanated from the South in 1995, Aykut and Ratha (2004) report that almost $40 \%$ of such flows now have origins in the other emerging markets.

${ }^{6}$ Institutional similarities among developing countries have also been proposed as an explanation for the recent surge in South-South FDI. See Dixit (2011).
} 
subsidiary sales of a broad range of source countries, and we show how these flows correlate with the absolute value of the difference in per capita income between origin and destination markets. In Section 3, we present our multi-country model of trade that includes non-homothetic preferences, monopolistic competition, and the proximity-versus-concentration tradeoff. In Section 4, we find conditions for FDI in a given product across country-pairs, taking as given the market size for that product in each country. We show that there is a bias towards FDI flows between countries with similarly sized markets for goods of a given quality level. Section 5 characterizes the global pattern of specialization and FDI in goods with different quality when countries differ in their income distributions and number of consumers. We present parameter configurations that give rise to Northern multinationals in high-quality goods and Southern multinationals in low-quality products. Section 6 concludes.

\section{Some Motivating Evidence on Bilateral Patterns of FDI}

Ramondo (2011) has assembled data on revenues from sales in country $j$ by foreign affiliates of firms based in country $i$, on accumulated stocks of foreign investment, and on other variables relating to bilateral FDI and foreign affiliate activity for 151 countries at different levels of development for the period from 1990 to 2002. We use these data to develop some motivating facts about the patterns of FDI and subsidiary sales. We are particularly interested in how these bilateral relationships reflect the similarity or difference in the per capita levels of the source and destination countries. ${ }^{7}$

In Figure 1, we plot on the horizontal axis the log of the average per capita income during the 1990's for the 129 (source) countries in the Ramondo data set that report positive stocks of outward FDI during the period. On the vertical axis we plot the log of the weighted average per capita income in the destination countries for this accumulated FDI, where the weights are the shares of each of the destination countries in the total stock of FDI originating in the particular source country. The figure shows clearly that firms based in rich countries tend to locate their foreign affiliates in richer destination markets than do firms based in poor countries. ${ }^{8}$ For example, the average per capita income in destination countries for FDI originating in the United States, France and Japan was $\$ 17,717, \$ 22,108$, and $\$ 19,396$, respectively, whereas for Chile, India and Russia it was $\$ 7025, \$ 8419$ and $\$ 11,882$. Meanwhile, Kenya and Nigeria directed their FDI to countries with weighted average per capita incomes of $\$ 570$ and $\$ 2398$, respectively.

Table 1 shows the results from a regression of the log of the average stock of bilateral FDI during the period from 1990 to 2000 on the absolute value of the log difference in per capita income between the origin and destination countries, the log of the geographic distance between the origin

\footnotetext{
${ }^{7}$ We are grateful to Natalia Ramondo for sharing these data with us and for advising us on details of how they were constructed.

${ }^{8}$ In a similar vein, the UNCTAD (2006) reports data on the FDI flows emanating from developing countries. They documents a negative correlation between GDP per capita and the share of developing economies in total FDI inflows. For example, between 2002 and 2004, between $70 \%$ and $80 \%$ of FDI flows into low-income countries such as China, Thailand or Paraguay originated from developing countries, while less than $20 \%$ did so in Switzerland, Japan or the United States (see UNCTAD 2006, Fig III.9, p.120).
} 


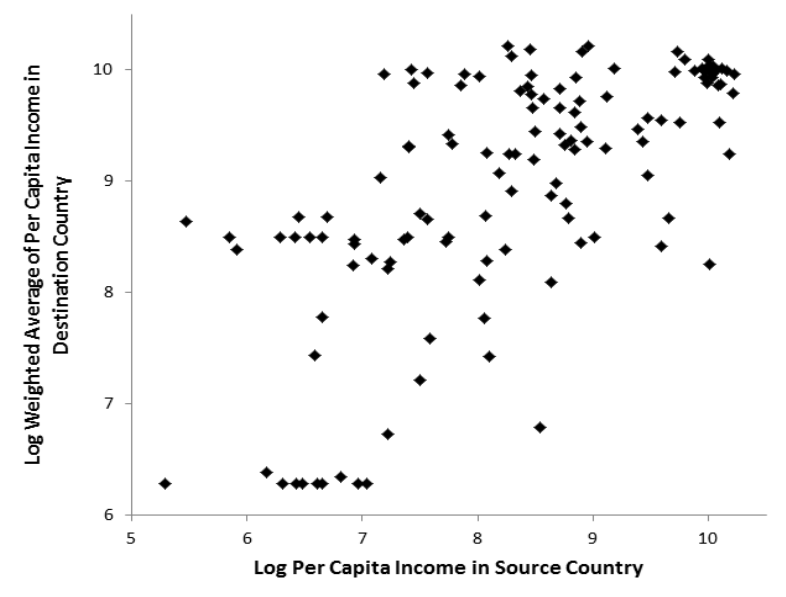

Figure 1: Per Capita Income for Source and Destination Countries for FDI

and destination countries, fixed effects for the origin and destination countries, and a constant, for the 2593 dyads that report positive stocks of FDI during the decade. The coefficient on the income gap variable is -0.36 , with a standard error of .06 . That is, a $10 \%$ increase in the ratio of per capita incomes between the origin and destination countries is associated with a $3.6 \%$ smaller stock of FDI from one to the other, after controlling for the fixed characteristics of the countries as sources of and destinations for FDI, and for their geographic proximity. The table also shows the results from a similar regression using data for revenues from foreign affiliate sales for the smaller number of 820 dyads that report such sales. The estimated coefficient on the log income difference is -0.64 in this regression, with a standard error of 0.28 .

The patterns revealed by the Ramondo data on FDI and affiliate sales, along with the earlier evidence for the United States provided by Brainard (1997) suggest that firms are more likely to serve via FDI those foreign markets that have similar per capita income to their home market compared to markets that have very different levels of per capita income. We now present a model of FDI featuring non-homothetic preferences for goods of different quality to explain why this might be so.

\section{The Model}

We study a world economy comprising four countries, two in the North and two in the South. We index the countries by $k \in\left\{\mathcal{R}_{1}, \mathcal{R}_{2}, \mathcal{P}_{1}, \mathcal{P}_{2}\right\}$. The pair of Northern countries, $\mathcal{R}_{1}$ and $\mathcal{R}_{2}$, have higher per capita incomes than do the pair of Southern countries, $\mathcal{P}_{1}$ and $\mathcal{P}_{2}$. We include four countries in our model in order to study foreign direct investment within and across levels of 
Table 1: Patterns of Bilateral FDI

Log of Average Stock Log of Average Revenues from of FDI, 1990-1999 Foreign Affiliate Sales, 1990-1999

$\begin{array}{ccc}\text { Absolute Diff. in } & -0.36 & -0.64 \\ \text { Log of Per Capita GDP } & (0.06) & (0.28) \\ & & -1.19 \\ \text { Log of Geographic } & -1.26 & (0.09) \\ \text { Distance } & (0.05) & 820 \\ & 2523 & .84 \\ \text { No. of Observations } & .76 & \\ \quad R^{2} & \end{array}$

development. For ease of exposition, we refer to the North and South as "regions", even though we adopt a symmetric geography in which it is equally costly to ship goods between any pair of countries.

Each country is populated by a continuum of households. A household is endowed with one unit of labor of some productivity. We take the distribution of labor productivity in each country as given and denote by $G^{k}(y)$ the fraction of households in country $k$ that has productivity less than or equal to $y$. Let $N^{k}$ be the measure of households residing in country $k$, so that $N^{k} \int y d G^{k}(y)$ is the aggregate supply of effective labor there.

\subsection{Supply}

In every country, competitive firms can produce a homogeneous, numeraire good with one unit of effective labor per unit of output. This good can be shipped internationally at zero cost. Labor supplies are such that every country produces the numeraire good in positive quantity. This pins down the common, global wage for effective labor and it implies that a household with $y$ units of effective labor has a labor income of $y$. Since there are no profits in the equilibria that we study, $G^{k}(y)$ gives the distribution of income in country $k$.

Agents in any country can access a common technology for producing a set of differentiated products. These goods can be produced in two different quality levels, $H$ and $L$, with $H>L$. At each quality level, the market delivers a discrete (and endogenous) number of horizontallydifferentiated varieties. In order to produce a good of quality $q$, a firm must bear a fixed cost of $f_{q}$ (i.e., it needs to hire $f_{q}$ units of effective labor) and a variable cost of $c_{q}$ per unit of output, with $f_{H} \geq f_{L}$ and $c_{H} \geq c_{L}$. We denote by $J_{q}$ the set of varieties with quality $q$ and by $J \equiv J_{H} \cup J_{L}$ the set of all available varieties.

A firm can serve its home market at no additional marketing cost. The firm has two options for supplying any foreign market. It can export a differentiated product with quality $q$ by paying $\tau_{q}$ per unit in international shipping costs. Alternatively, it can open a plant in a foreign country 
and produce there for local sales, or indeed for sales to anywhere in the world. A subsidiary incurs no shipping costs for local sales in the country where the plant is located, but sales from an export platform bear the same shipping $\operatorname{costs} \tau_{q}$ as do other export sales. A firm must pay $h_{q}$ in plant fixed costs for each of its foreign subsidiaries. The choice of FDI versus exporting entails the familiar, proximity-concentration tradeoff, as in Brainard (1993) and Horstmann and Markusen (1992).

\subsection{Demand}

Each household demands exactly one unit of some variety of the differentiated product. A household $h$ that consumes $z$ units of the homogenous good and chooses variety $j \in J_{q}$ of the differentiated product achieves utility

$$
u_{j}^{h}=z q+\varepsilon_{j}^{h},
$$

where $\varepsilon_{j}^{h}$ is the household's idiosyncratic evaluation of the attributes of that variety. Each household has a vector $\varepsilon^{h}=\left\{\varepsilon_{j}^{h}\right\}$ of such taste parameters. A household maximizes utility by making a discrete choice of some particular variety in some quality segment and by spending its residual income on the homogeneous good. We assume that, in every country, even the household with the least income can afford to purchase the most expensive brand of the differentiated product. In every country, the vectors $\varepsilon^{h}$ are distributed independently across households according to the Generalized Extreme Value (GEV) distribution,

$$
G_{\varepsilon}(\varepsilon)=e^{-\sum_{q \in\{L, H\}}\left[\sum_{j \in J_{q}} e^{-\varepsilon_{j} / \theta_{q}}\right]^{\theta_{q}}}, \text { with } 0<\theta_{L}<\theta_{H}<1 \text {. }
$$

In Fajgelbaum et al. (2011), we discussed how aggregate demands are derived from these preferences, given a set of prices $\left\{p_{j}^{k}\right\}$ for all products sold in country $k$; in so doing, we followed the methods developed by McFadden (1978) and others. As is well known from the literature on discrete choice, the GEV distribution of the taste parameter implies that

$$
\rho_{j}^{k}(y)=\frac{e^{-p_{j}^{k} q / \theta_{q}}}{\sum_{\ell \in J_{q}} e^{-p_{\ell}^{k} q / \theta_{q}}} \frac{\left[\sum_{j^{\prime} \in J_{q}} e^{\left(y-p_{j^{\prime}}^{k}\right) q / \theta_{q}}\right]^{\theta_{q}}}{\sum_{\omega \in\{H, L\}}\left[\sum_{\ell \in J_{\omega}} e^{\left(y-p_{\ell}^{k}\right) \omega / \theta_{\omega}}\right]^{\theta_{\omega}}} \text { for } j \in J_{q}, q=\{H, L\} .
$$

where $\rho_{j}^{k}(y)$ is the fraction of households with income $y$ that chooses variety $j$ in country $k$ at the given prices. Variation in the spending pattern across income groups in a country arises solely from variation in the fraction of individuals who purchase the products at different levels of quality $q$, as reflected by the functions $\rho_{j}^{k}(y)$. As shown in Fajgelbaum et al. (2009), the fraction of individuals who purchase high-quality products rises with income at all income levels. Aggregate demands for 
any product are found by integrating the sales over all income groups, so that

$$
d_{j}^{k}=\frac{N^{k} e^{-p_{j}^{k} q / \theta_{q}}}{\sum_{j^{\prime} \in J_{q}} e^{-p_{j^{\prime}}^{k} q / \theta_{q}}} \int\left\{\frac{\left[\sum_{j^{\prime} \in J_{q}} e^{\left(y-p_{j^{\prime}}^{k}\right) q / \theta_{q}}\right]^{\theta_{q}}}{\sum_{\omega \in\{H, L\}}\left[\sum_{\ell \in J_{\omega}} e^{\left(y-p_{\ell}^{k}\right) \omega / \theta_{\omega}}\right]^{\theta_{\omega}}}\right\} \mathrm{d} G^{k}(y)
$$

where $d_{j}^{k}$ is the demand for brand $j \in J_{q}$ in country $k$. The reader will recognize (2) as a nested logit system of aggregate demands.

\subsection{Pricing and Profits}

Each firm that produces some variety of the differentiated product sells its output to consumers worldwide. The firm can choose different prices in each market although in fact it has no incentive to discriminate in its f.o.b. prices. A firm that produces a variety $j \in J_{q}$ in country $k$ faces aggregate demand $d_{j}^{k}$ in its home market and a unit cost of $c_{q}$. We assume that the number of active producers in each quality segment is large and that monopolistic competition prevails. As is common in settings with monopolistic competition, the fact that there are many competitors means that firms can ignore the influence of their own price decisions on the terms in the various sums in (2). As we have shown in Fajgelbaum et al. (2011), the profit-maximizing price for local sales entails a fixed markup $\theta_{q} / q$ over marginal cost.

Each firm in country $k$ serves the foreign market in another country $k^{\prime}$ either with exports or with goods produced in a subsidiary there, but not both. Firms with subsidiaries in $k^{\prime}$ face the same demand and cost conditions as local producers, so they too price at a markup $\theta_{q} / q$ over their unit cost of $c_{q}$. Firms that export to country $k^{\prime}$ face a higher cost per sale of $c_{q}+\tau_{q}$ that includes a shipping charge. So, they price at a markup $\theta_{q} / q$ over this higher, delivered cost. In short, households in any country $k$ face at most two prices for the varieties in $J_{q}$, the price $p_{q}^{d}$ that is charged for all locally-produced goods and the price $p_{q}^{m}$ that is attached to imports. These prices are common across countries and given by

$$
\left.\begin{array}{c}
p_{q}^{d}=c_{q}+\frac{\theta_{q}}{q} \\
p_{q}^{m}=c_{q}+\tau_{q}+\frac{\theta_{q}}{q}
\end{array}\right\} \text { for } q=H, L .
$$

The markups vary positively with the "dissimilarity" parameter $\theta_{q}$ for goods in $J_{q}$ and negatively with the quality level itself. A high value for $\theta_{q}$ implies that goods in $J_{q}$ are imperfect substitutes in aggregate demand, in the sense that the idiosyncratic tastes for any pair of these goods are little correlated. This makes for an inelastic demand for a given variety and thus a large markup. The direct effect of quality is to raise households' marginal utility of spending on the homogeneous good, which makes them more sensitive to prices and thus induces a lower markup. Taken together, these considerations imply a higher markup for high-quality products than for low-quality goods if and only if $\theta_{H} / H>\theta_{L} / L$; see Fajgelbaum et al. (2011) for further discussion. 
Sales of locally-produced goods of quality $q$ in country $k$ (be they domestic brands or those of foreign subsidiaries) reflect the prices of these goods, the prices of competing imports, and the numbers of locally-produced and imported varieties at each quality level. Let $d_{q}^{k}$ represent the aggregate demand by domestic consumers for a typical good of quality $q$ produced in country $k$ by a domestic firm or by a foreign subsidiary, when all goods are priced according to (3). Then the demand function (2) implies

$$
d_{q}^{k}=\frac{N^{k}}{\tilde{n}_{q}^{k}} \mathbb{E}^{k}\left[\frac{\left(\tilde{n}_{q}^{k}\right)^{\theta_{q}} \phi_{q}(y)}{\left(\tilde{n}_{H}^{k}\right)^{\theta_{H}} \phi_{H}(y)+\left(\tilde{n}_{L}^{k}\right)^{\theta_{L}} \phi_{L}(y)}\right], \quad \text { for } q=H, L \text { and all } k
$$

where

$$
\begin{gathered}
\tilde{n}_{q}^{k} \equiv n_{q}^{k}+\lambda_{q} n_{q}^{m, k}, \\
\lambda_{q} \equiv e^{-\tau_{q} q / \theta_{q}}, \\
\phi_{q}(y) \equiv e^{\left(y-c_{q}\right) q-\theta_{q}},
\end{gathered}
$$

$n_{q}^{k}$ is the number of varieties of goods of quality $q$ produced in country $k, n_{q}^{m, k}$ is the number of varieties of goods of quality $q$ imported into country $k$, and $\mathbb{E}^{k}$ is the expectation operator with respect to the income distribution in country $k$. The aggregate sales in country $k$ of a typical imported variety with quality $q$ are a fraction $\lambda_{q}$ of sales by local producers. The number of products $n_{q}^{k}$ consists of goods produced by domestic firms in country $k, n_{q}^{d, k}$, and goods produced by foreign subsidiaries in country $k, n_{q}^{s, k}$, i.e., $n_{q}^{k}=n_{q}^{d, k}+n_{q}^{s, k}$. The number $n_{q}^{m, k}$ includes exporters from as many as three source countries and similarly, the number $n_{q}^{s, k}$ includes FDI in $k$ from as many as three parent countries. We refer to $\tilde{n}_{q}^{k}$ as the "effective" number of competitors in the market segment for quality $q$ in country $k$, after taking into account the equilibrium pricing induced by the positive transport costs; i.e., after appropriately discounting the number of imported varieties.

All firms that produce a variety with quality $q$ earn the same variable profits of $\theta_{q} / q$ per unit sold. A domestic firm in country $k$ makes local sales of $d_{q}^{k}$ and pays no "extra" fixed costs. Its variable profits in its home market are the product of its sales and the mark-up. A foreign firm with a subsidiary in $k$ makes these same sales, but pays a fixed cost for its foreign plants of $h_{q}$. Its profits in the market are those of the domestic firm less the fixed cost of the subsidiary. An exporter to country $k$ bears no extra fixed cost for selling there, but its sales in country $k$ are only $\lambda_{q}$ times as large as those of a typical, local producer. Thus, we can express profits from sales in country $k$ by a domestic firm, by a local subsidiary of a foreign firm, and by a foreign exporter, respectively, as

$$
\left.\begin{array}{c}
\pi_{q}^{d, k}=d_{q}^{k} \frac{\theta_{q}}{q}, \\
\pi_{q}^{s, k}=d_{q}^{k} \frac{\theta_{q}}{q}-h_{q}, \\
\pi_{q}^{x, k}=\lambda_{q} d_{q}^{k} \frac{\theta_{q}}{q}
\end{array}\right\} \quad \text { for } q=H, L \text { and all } k
$$

Of course, each foreign firm chooses its mode for serving market $k$ by comparing potential profits 
from exporting $\pi_{q}^{x, k}$ with potential profits from subsidiary sales, $\pi_{q}^{s, k}$; a firm that produces a variety with quality $q$ engages in FDI in country $k$ if $\pi_{q}^{s, k}>\pi_{q}^{x, k}$, it exports to $k$ if $\pi_{q}^{s, k}<\pi_{q}^{x, k}$, and it is indifferent otherwise. The maximum global profit attainable by a firm with headquarters in country $\ell$ that produces a brand with quality $q$ is

$$
\pi_{q}^{\ell}=\pi_{q}^{d, \ell}+\sum_{k \in\left\{\mathcal{R}_{1}, \mathcal{R}_{2}, \mathcal{P}_{1}, \mathcal{P}_{2}\right\}, k \neq \ell} \max \left\{\pi_{q}^{x, k}, \pi_{q}^{s, k}\right\}-f_{q} .
$$

We assume that there is free entry into the market for differentiated products, so that $\pi_{q}^{\ell}=0$ in an equilibrium in which a positive number of firms that produce goods with quality $q$ are headquartered in country $\ell$, and $\pi_{q}^{\ell} \leq 0$ in an equilibrium in which no firms that produce goods with this quality are headquartered there. ${ }^{9}$

\subsection{Equilibrium}

To summarize, an equilibrium in our model consists of (local) market potentials $\left\{d_{q}^{k}\right\}$ for each market $k \in\left\{\mathcal{R}_{1}, \mathcal{R}_{2}, \mathcal{P}_{1}, \mathcal{P}_{2}\right\}$ and product quality $q \in\{H, L\}$, numbers of domestic producers $\left\{n_{q}^{d, k}\right\}$ in country $k$ and market segment $q$, numbers of firms $\left\{n_{q}^{m, k}\right\}$ exporting to country $k$ a variety of quality $q$, and numbers of firms $\left\{n_{q}^{s, k}\right\}$ with a foreign subsidiary situated in country $k$ to manufacture a variety with quality $q$, such that $n_{q}^{s, k}+n_{q}^{m, k}=\sum_{l \neq k} n_{q}^{d, l}$ for all $k$ and $q$, and

(i) given the numbers and organizational choices of all firms, local market potentials satisfy (4);

(ii) given market potentials $\left\{d_{q}^{k}\right\}$, the export versus FDI decisions of all firms are optimal; i.e.,

$$
\pi_{q}^{x, k}<\pi_{q}^{s, k} \Rightarrow n_{q}^{m, k}=0 \text { and } \pi_{q}^{s, k}<\pi_{q}^{x, k} \Rightarrow n_{q}^{s, k}=0
$$

(iii) and given market potentials $\left\{d_{q}^{k}\right\}$, the numbers of entrants in each market and market segment are consistent with free entry; i.e.,

$$
n_{q}^{d, k}>0 \Rightarrow \pi_{q}^{k}=0 \text { and } n_{q}^{d, k}=0 \Rightarrow \pi_{q}^{k} \leq 0
$$

The "market potential" $d_{q}^{k}$ measures the number of sales that a local producer of some variety with quality $q$ could capture in country $k$, considering the number and location of its competitors, the optimal pricing decision by the firm and all its rivals, and the overall size of the market.

In what follows, we consider first a world economy in which $\mathcal{R}_{1}$ and $\mathcal{R}_{2}$ are a pair of symmetric countries and $\mathcal{P}_{1}$ and $\mathcal{P}_{2}$ also are symmetric. In other words, we suppose that each region comprises two countries that are identical in all relevant respects. We do allow the distribution of income

\footnotetext{
${ }^{9}$ Actually, the integer constraint on the numbers of firms allows for (small) positive profits in equilibrium, so long as a potential entrant in any market segment and country would break even or suffer losses. In what follows, we neglect this detail, and treat the numbers of firms as continuous variables that generate zero profits for active firms in all countries and quality segments.
} 
and the population size to differ between North and South. For the case of symmetric countries within each region, we can drop the subscripts 1 and 2 from the countries and use $\mathcal{R}$ to indicate a typical (rich) country in the North and $\mathcal{P}$ to indicate a typical (poor) country in the South. With this notation in place, the net profits of a firm headquartered in country $k$ that produces a brand of quality $q$ can be written as

$$
\pi_{q}^{k}=d_{q}^{k} \frac{\theta_{q}}{q}+\max \left\{\lambda_{q} d_{q}^{k} \frac{\theta_{q}}{q}, d_{q}^{k} \frac{\theta_{q}}{q}-h_{q}\right\}+2 \max \left\{\lambda_{q} d_{q}^{\ell} \frac{\theta_{q}}{q}, d_{q}^{\ell} \frac{\theta_{q}}{q}-h_{q}\right\}-f_{q}
$$

for $q=H, L, k, \ell=\mathcal{R}, \mathcal{P}$ and $\ell \neq k$. Following our analysis of the symmetric case in the next two sections, we shall discuss some consequences of asymmetries between the countries in a region.

\section{Place of Entry and Conditions for FDI}

We are interested in where firms enter in each quality segment and how the active producers choose to serve their various foreign markets. In this section, we will focus on the profitability conditions that determine the place of entry and mode of organization. We will ask, What combinations of market potentials, $d_{q}^{\mathcal{R}}$ and $d_{q}^{\mathcal{P}}$, are consistent with zero profits for active firms, non-positive profits for potential entrants, and optimal organization of production by all firms? In other words, we will identify the combinations of $d_{q}^{\mathcal{R}}$ and $d_{q}^{\mathcal{P}}$ that satisfy the requirements (ii) and (iii) in the definition of an equilibrium that we gave in Section 3.4, without considering for the time being which ones are also consistent with the demand system, as stipulated in requirement (i). In so doing, we are able to establish and explain a general bias in favor of North-to-North and South-to-South multinationals. In the next section, we will impose requirement (i) in order to fully characterize the general equilibrium.

Let us focus on the market for differentiated products with quality $q$ and omit the subscript $q$ whenever it causes no confusion to do so. We define two magnitudes that will be important in the discussion. First, let $x$ be the volume of sales that a firm would need to make in order to cover its fixed cost of entry. Inasmuch as firms make the same profit $\theta / q$ on every sale in any of the four markets, it follows that $x=f q / \theta$. Second, let $x^{s}$ be the volume of sales that a firm must make in some foreign market in order to cover the cost of operating a subsidiary there. Then $x^{s}=h q / \theta$. Note that both $x$ and $x^{s}$ are derived parameters; i.e., they do not depend on any of the equilibrium interactions in the model.

Using these definitions, we can represent the net profits of a firm as given in (6) more compactly as

$$
\pi^{k}=\frac{\theta}{q}\left[d^{k}+\max \left\{\lambda d^{k}, d^{k}-x^{s}\right\}+2 \max \left\{\lambda d^{\ell}, d^{\ell}-x^{s}\right\}-x\right]
$$

for $k, \ell=\mathcal{R}, \mathcal{P}$ and $\ell \neq k$, where $d^{k}$ are the sales in country $k$ of a typical product manufactured locally and $\lambda d^{k}$ are the sales of an imported product. Clearly, the choice between exporting to a foreign market and opening a subsidiary is governed by a comparison of $\lambda d^{k}$ and $d^{k}-x^{s}$; a non-local firm will serve the market in country $k$ by exports if $d^{k}<x^{s} /(1-\lambda)$ and by subsidiary sales if the 
opposite inequality holds. In other words, large markets are served by foreign subsidiaries to avoid the substantial shipping costs that would result from trade, whereas smaller markets are served by exports because the potential cost savings from local delivery cannot justify the cost of investment in a local plant. Also, the break-even condition for firms headquartered in country $k$ requires that

$$
d^{k}+\max \left\{\lambda d^{k}, d^{k}-x^{s}\right\}+2 \max \left\{\lambda d^{\ell}, d^{\ell}-x^{s}\right\}=x
$$

for $k, \ell=\mathcal{R}, \mathcal{P}$ and $\ell \neq k$; if the left-hand side of (7) falls short of $x$, then no firms will enter in country $k$ in the relevant market segment.

Considering the symmetry that we have introduced, there are four possible outcomes for a firm's choice of how to serve its foreign markets. At one extreme, a firm headquartered in some country may choose to supply all foreign markets as an exporter. At the opposite extreme, the firm might elect to establish foreign subsidiaries in all markets; we shall refer to such a firm as a global multinational. We are, however, most interested in the conditions that give rise to the intermediate outcomes, in which a firm serves some markets with exports and others by subsidiary sales. We refer to a firm that operates a subsidiary in the other country in its own region but exports to the two markets in the opposite region as a regional multinational. A firm that exports to the other market in its own region but operates subsidiaries in the opposite region is a cross-regional multinational.

We now begin to identify the combinations of $d^{\mathcal{R}}$ and $d^{\mathcal{P}}$ that are consistent with entry in either region (or both) and with the various organizational choices. We start with the cross-regional multinationals, for which the conditions are most restrictive. Suppose that a firm headquartered in country $k$ exports to country $k^{\prime}$ in its own region, but operates a subsidiary in the two countries $\ell$ and $\ell^{\prime}$ in the opposite region. Exports from $k$ to $k^{\prime}$ can be optimal for the firm only if $d^{k} \leq x^{s} /(1-\lambda)$. Moreover, the firm breaks even only if

$$
(1+\lambda) d^{k}+2 d^{\ell}=x+2 x^{s}
$$

Of course, there can be no pure-profit opportunities for a firm that might enter in the same quality segment in country $\ell$ and operate as a regional multinational from there, which implies that

$$
2 d^{\ell}+2 \lambda d^{k} \leq x+x^{s}
$$

Together, (8) and (9) imply that $d^{k} \geq x^{s} /(1-\lambda)$. Therefore, a firm might enter in country $k$ and operate as a cross-regional multinational only if $d^{k}=x^{s} /(1-\lambda)$. The presence of crossregional multinationals based in country $k$ also requires that $d^{\ell} \geq x^{s} /(1-\lambda)$, because otherwise the firm would prefer to export to the two markets in the opposite region. In short, cross-regional multinationals can emerge only in one of the smaller markets, and then only for a very particular value of the market potential there.

As we turn to the other organizational forms, we will distinguish three cases based on the relative 


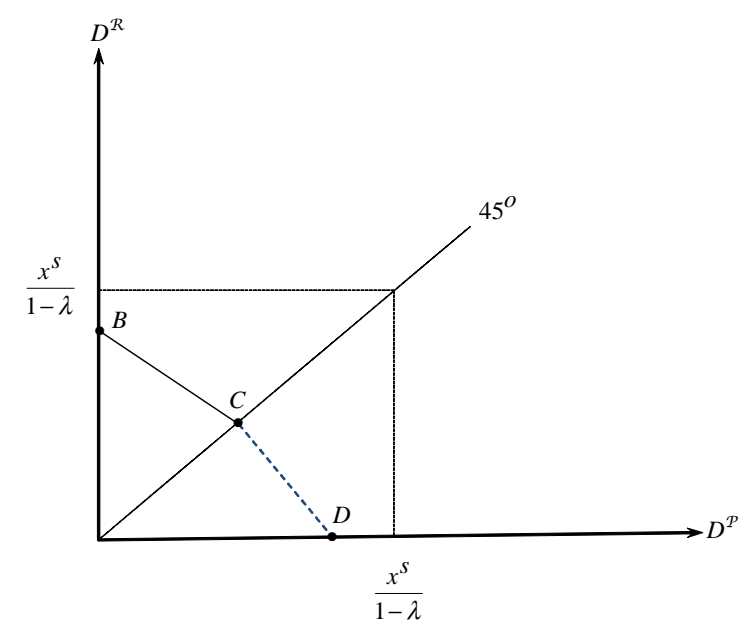

Figure 2: Market potentials with prohibitive FDI costs: $x^{s} / x>(1-\lambda) /(1+\lambda)$

size of the fixed cost of operating a foreign subsidiary compared to the fixed cost of entering the market. Note that $x^{s} / x=h / f$. We say that the relative cost of FDI is prohibitive if $x^{s} / x>$ $(1-\lambda) /(1+\lambda)$, it is high if $(1-\lambda) /(1+\lambda)>x^{s} / x>(1-\lambda) /(1+3 \lambda)$ and it is low if $x^{s} / x<$ $(1-\lambda) /(1+3 \lambda)$.

Figure 2 illustrates a case in which the relative cost of FDI is prohibitive. The solid line depicts combinations of $d^{\mathcal{R}}$ and $d^{\mathcal{P}}$ such that exporters in the North break even; namely, $(1+\lambda) d^{\mathcal{R}}+$ $2 \lambda d^{\mathcal{P}}=x$. Similarly, the broken line depicts combinations of the market potentials such that exporters in the South earn zero profits, or $(1+\lambda) d^{\mathcal{P}}+2 \lambda d^{\mathcal{R}}=x$. These are the only possible outcomes when there is such a relatively high cost of FDI, because foreign subsidiaries can never operate profitably under such conditions. ${ }^{10}$ The equilibrium can have active firms in both regions only at point $C$, were $d^{\mathcal{R}}=d^{\mathcal{P}}$. Otherwise, the North alone will produce and export the good in question (if $d^{\mathcal{R}}>d^{\mathcal{P}}$ ) or the South alone will do so (if $d^{\mathcal{R}}<d^{\mathcal{P}}$ ). Note, for example, that if $d^{\mathcal{R}}>d^{\mathcal{P}}$ and exporters in the South were to break even, then exporters in the North would have an opportunity to make strictly positive profits.

Now consider Figure 3, which illustrates the case of a high (but not prohibitive) relative cost of FDI. The solid line segments in the figure represent combinations of $d^{\mathcal{R}}$ and $d^{\mathcal{P}}$ such that firms located in the North make zero profits under their most profitable organizational form and for which entry in the South would be unprofitable. Similarly, the broken line segments represent combinations of $d^{\mathcal{R}}$ and $d^{\mathcal{P}}$ that yield zero profits for Southern firms under their optimal choice of exporting versus FDI and for which entry by Northern firms would be unprofitable. At point $C$, all producers face similar profit opportunities no matter where they are headquartered, so if firms in the North break even, firms in the South do so as well.

\footnotetext{
${ }^{10}$ Suppose that a regional multinational operates in country $k$. Then $2 d^{k}+2 \lambda d^{\ell}=x+x^{s}$ and $d^{k} \geq x^{s} /(1-\lambda)$. Together, these imply $(1-\lambda) /(1+\lambda) \geq x^{s} / x$.

Now suppose that a global multinational operates in country $k$. Then $2 d^{k}+2 d^{\ell}=x+3 x^{s}, d^{k} \geq x^{s} /(1-\lambda)$, and $d^{\ell} \geq x^{s} /(1-\lambda)$. Again these imply $(1-\lambda) /(1+\lambda) \geq x^{s} / x$.
} 


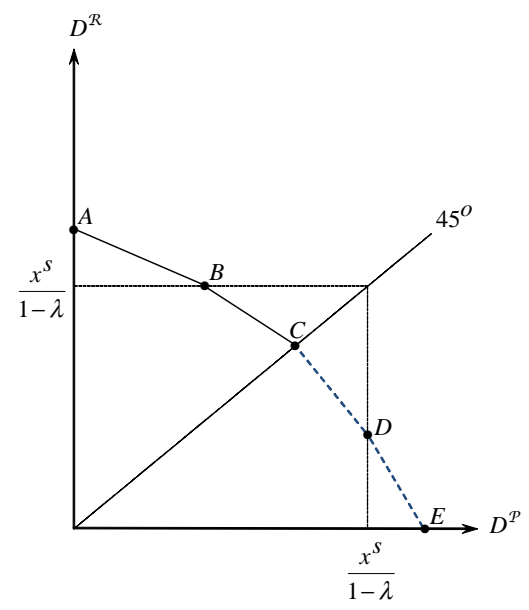

Figure 3: Market potentials with high FDI costs: $(1-\lambda) /(1+3 \lambda)<x^{s} / x<(1-\lambda) /(1+\lambda)$

Notice that at point $C, d^{\mathcal{R}}=d^{\mathcal{P}}<x^{s} /(1-\lambda)$. Point $C$ lies on the two curves representing the zero-profit conditions for exporters in each region; i.e., at point $C$

$$
(1+\lambda) d^{\mathcal{R}}+2 \lambda d^{\mathcal{P}}=x
$$

and

$$
(1+\lambda) d^{\mathcal{P}}+2 \lambda d^{\mathcal{R}}=x
$$

so that $d^{\mathcal{R}}=d^{\mathcal{P}}=x /(1+3 \lambda)$. The fact that, at point $C$, each market potential is less than $x^{s} /(1-\lambda)$ follows from the condition for a high relative cost of FDI. It implies that, with these value of the market potentials, no firm would find it profitable to open a foreign subsidiary anywhere in the world.

Along the interior of $B C$, the break-even condition (10) for exporters located in a Northern country is satisfied. Since all these points represent market potentials less than $x^{s} /(1-\lambda)$ in both markets, no Northern firm would be tempted to open any foreign subsidiary. Moreover, when firms in the North break even for such values of $d^{\mathcal{R}}$ and $d^{\mathcal{P}}$, firms in the South cannot profitably survive. Thus, the points along $B C$ represent possible outcomes with exporting firms headquartered in the North and no production in the South. Similarly, points along the interior of $C D$ represent market potentials consistent with exporting firms headquartered in the South, but no entry in the North, and no FDI.

At point $B$, a Northern firm would be indifferent between exporting to the other regional market or operating a subsidiary there. At this point, both of these modes yield the same profits and either could be consistent with the equilibrium requirements. The segment $A B$ represents combinations of $d^{\mathcal{R}}$ and $d^{\mathcal{P}}$ for which a regional multinational headquartered in the North makes zero profits; i.e.,

$$
2 d^{\mathcal{R}}+2 \lambda d^{\mathcal{P}}=x+x^{s}
$$




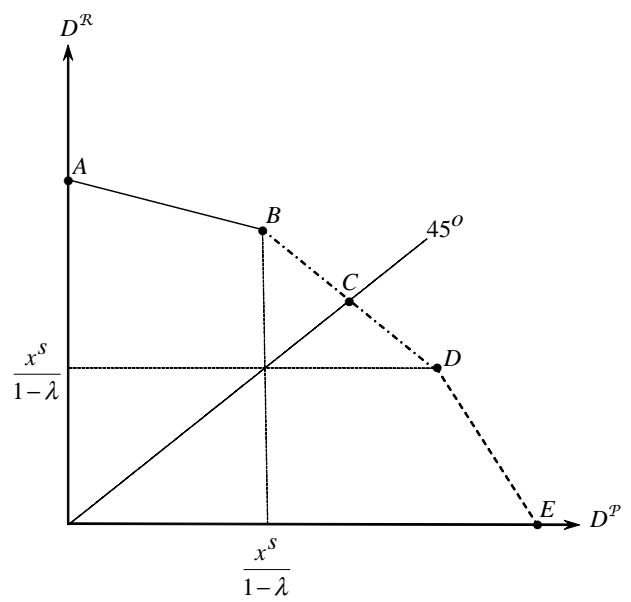

Figure 4: Market potentials with low FDI costs: $x^{s} / x<(1-\lambda) /(1+3 \lambda)$

In the interior of this segment, Northern firms strictly prefer to export to the South but also strictly prefer to operate a subsidiary in the regional market that is not their own. Moreover, if the market potentials are such that regional multinationals break even in the North, there will be no profitable entry opportunity for any type of firm in the South. The segment $D E$ has similar properties, except that the regional multinationals would be headquartered in the South instead of the North.

We see that three types of outcomes are possible for the case of a high cost of FDI. First, the market potentials may be the same in all countries (point $C$ ), in which case there may be active firms in any market but all producers serve their foreign markets as exporters. Second, entry may be confined to one region (in the North along $B C$ and in the South along $C D$ ), with all firms again serving foreign markets via trade. Finally, entry may take place in only one region (in the North along $A B$ and in the South along $D E$ ), with active firms serving their home market with domestic sales, the two markets in the opposite region with exports, and the market in the remaining country in their own region with goods produced in a subsidiary there. Notice that this last outcome exhibits FDI from North to North or from South to South, but not from North to South.

We turn to Figure 4, which depicts the case of a low relative cost of FDI. Again, the solid line segment indicates that firms are active only in the North, whereas the broken segment indicates that firms are active only in the South. Here, there is also a dotted-and-dashed segment, which is meant to suggest that producers may operate profitably with headquarters located anywhere in the world.

Consider first point $C$, where the market potentials in the two regions are the same. At this point, $d^{\mathcal{R}}=d^{\mathcal{P}}>x^{s} /(1-\lambda)$, so no matter where a firm is headquartered, it prefers to open a subsidiary in each of its three foreign markets than to export from the home plant to any of them. All firms operate as global multinationals, and entry is equally profitable in any location. But notice, now, that the same is true all along the segment $B C$. As long as the market potential in 
every country exceeds $x^{s} /(1-\lambda)$, all active firms choose to be global multinationals. And global multinationals make the same sales, earn the same revenues and pay the same fixed and variable costs irrespective of their country of origin.

The segment $A B$ in Figure 4 represents combinations of $d^{\mathcal{R}}$ and $d^{\mathcal{P}}$ that give rise to regional multinationals with their headquarters in the North, while the segment $D E$ represents combinations for which there are regional multinationals headquartered in the South. In either case, the market potential in a firm's regional foreign market exceeds the critical value that makes FDI profitable, but the market potentials in the countries of the opposite region do not. In other words, segment $A B$ has North-to-North FDI, while segment $D E$ has South-to-South FDI, but neither segment has FDI that cross regional boundaries.

We summarize our findings in

Proposition 1 (a) If $h_{q} / f_{q}<\left(1-\lambda_{q}\right) /\left(1+3 \lambda_{q}\right)$, there is FDI for products of quality $q$. Either these goods are produced in the North and in the South and all firms engage in global FDI, or one region specializes in producing products of quality $q$. In the latter case, every firm serves the other country in its region with subsidiary sales while exporting to the countries in the opposite region.

(b) If $h_{q} / f_{q}>\left(1-\lambda_{q}\right) /\left(1+\lambda_{q}\right)$, there is international trade but no FDI in products of quality $q$. Production may take place in one or both regions, but in either case producers export to all foreign markets.

(c) If $\left(1-\lambda_{q}\right) /\left(1+\lambda_{q}\right)>h_{q} / f_{q}>\left(1-\lambda_{q}\right) /\left(1+3 \lambda_{q}\right)$, there is international trade in products of quality q. FDI can occur only when production takes place in a single region, and then every producer serves the country in its region with subsidiary sales while exporting to the countries in the opposite region.

The proposition immediately implies

Corollary 1 If FDI takes place for products of quality q, then there must be either North-to-North FDI or South-to-South FDI.

This corollary can help to explain the prevalence of multinational investment between and among the industrialized countries, as well as perhaps the recent dramatic rise of Southern multinationals operating in other developing countries. In terms of our model, the intuition is straightforward. In a world of costly trade and foreign investment, firms tend to enter into the larger markets. But with non-homothetic demands for vertically differentiated products, the large markets for a good of a given quality are likely to be found in countries that stand at similar levels of development. Moreover, the proximity-concentration tradeoff implies that firms prefer to serve large foreign markets with FDI and small markets with exports. It follows that regional FDI often will be more attractive to firms than cross-regional FDI. 


\section{$5 \quad$ Patterns of Trade and FDI}

In Section 4, we identified the combinations of $d^{\mathcal{R}}$ and $d^{\mathcal{P}}$ that are consistent with free entry and optimal choices of exporting versus FDI by all firms. Now we need to reintroduce the connection between the numbers and organizational choices of firms in each location and the sales that result from optimal pricing in order to pin down the equilibrium values of $d^{\mathcal{R}}$ and $d^{\mathcal{P}}$ in each market segment. In so doing, we can link the global patterns of FDI and trade to cost parameters, income distributions, and population sizes, which are the fundamental determinants of trade and FDI in our model. In all that follows, we assume that the typical country in the North is richer than the typical country in the South, in the sense that $G^{\mathcal{R}}(y)$ first-order stochastically dominates $G^{\mathcal{P}}(y)$.

\subsection{Fixed Costs of Foreign Direct Investment}

We begin by examining the cost of foreign investment, which is captured in our model by the parameters $h_{H}$ and $h_{L}$. For purposes of this exercise, we will assume that all countries have the same population size, $N$. We will examine the consequences of a reduction in the fixed cost of FDI in one quality segment while holding that in the other segment constant.

Suppose that the fixed cost of FDI is prohibitive in both quality segments, using the terminology introduced in Section 4; that is, $h_{q} / f_{q}>\left(1-\lambda_{q}\right) /\left(1+\lambda_{q}\right)$ for $q=H, L$. As we have noted, no multinational investment can arise in such circumstances and the equilibrium features exporting by all firms. The trade patterns can be found by extending the reasoning developed in Fajgelbaum et al. (2010). As we noted there, several subcases can arise. If shipping costs are high enough, they can afford enough protection to support positive production of both low-quality and high-quality goods in every country. A similar outcome arises for any given set of shipping costs if the income distributions of the two regions are sufficiently close. If shipping costs instead are low, or the income distributions of the two regions are far apart, each good will be produced in only one region. In such circumstances, the home-market effect renders entry in the smaller markets unprofitable. It is also possible that equilibrium production in one quality segment will be diversified globally while production in the other segment is concentrated in one region.

For the time being, let us examine the case in which, in the absence of any multinational investment, production of goods at each quality level takes place in only one region. The arguments from Fajgelbaum et al. (2010) readily extend to our setting with two symmetric countries in each region. They imply that goods of quality $H$ are produced in the countries that have the larger markets for these goods which, with equal populations and the specified differences in income distribution, must be the richer countries, $\mathcal{R}_{1}$ and $\mathcal{R}_{2}$. Similarly, when the fixed costs of FDI are prohibitive, the goods of quality $L$ are produced in $\mathcal{P}_{1}$ and $\mathcal{P}_{2}$. In terms of our Figure 2 , the discussion in Fajgelbaum et al. (2010) indicates that the equilibrium in the market for high-quality

goods falls somewhere along the segment $B C$, where $d_{H}^{\mathcal{R}}>d_{H}^{\mathcal{P}}$. Meanwhile, the equilibrium in the market for low-quality goods lies somewhere along $C D$, where $d_{L}^{\mathcal{P}}>d_{L}^{\mathcal{R}}$. The Northern countries export high-quality products to the South and the Southern countries export low-quality products 
to the North, with balanced trade between the countries in the same region.

Now suppose that the fixed cost of FDI falls for high-quality goods, and with it the minimum scale for a profitable subsidiary. As long as $h_{H}$ remains sufficiently large that $x_{H}^{s}>\left(1-\lambda_{H}\right) d_{H}^{\mathcal{R}}$ at the $d_{H}^{\mathcal{R}}$ of the trade-only equilibrium, then no firm has any incentive to change its mode of delivery or its prices. The equilibrium continues to feature exports as the sole means of delivery.

Once $h_{H}$ falls to a level at which this inequality no longer is satisfied at the initial $d_{H}^{\mathcal{R}}$, then FDI becomes an attractive alternative to exporting for some firms in the North. Let $h_{H}$ be such that $x_{H}^{s}=\left(1-\lambda_{H}\right) d_{H}^{\mathcal{R}}$ at the $d_{H}^{\mathcal{R}}$ of the trade-only equilibrium, while $h_{L}$ remains sufficiently high that $h_{L} / f_{L}>\left(1-\lambda_{L}\right) /\left(1+\lambda_{L}\right)$. Then firms that produce high-quality goods in the North are indifferent between serving the foreign market in their region with exports or by establishing a local presence there. In Figure 3, the equilibrium now is at a point such as $B$ in the market for highquality goods, and along $C D$ in the market for low-quality goods. Initially (i.e., for the greatest value of $h_{H}$ such that $\left.x_{H}^{s}=\left(1-\lambda_{H}\right) d_{H}^{\mathcal{R}}\right)$ the equilibrium continues to have only exporting and no FDI. We can see that regional multinationals must emerge in the North as the fixed cost of FDI falls from that level. In this circumstance, the trade-only equilibrium is no longer sustainable because $x_{H}^{s}<\left(1-\lambda_{H}\right) d_{H}^{\mathcal{R}}$ at the trade-only value for $d_{H}^{\mathcal{R}}$. Furthermore, as long as the fall in $h_{H}$ is not too large the economy must still be in a situation such as the one depicted in Figure 3 (i.e., where the relative cost of FDI is high according to our definition). Therefore, an equilibrium with regional multinationals turns out to be the only feasible outcome in this situation.

Note, further, that the equality $x_{H}^{s}=\left(1-\lambda_{H}\right) d_{H}^{\mathcal{R}}$ must continue to hold for some range of values of $h_{H}$. Otherwise, in the absence of any additional adjustments, the opening of a foreign subsidiary would be attractive to all Northern firms. But this would create a discontinuous response in the equilibrium, which cannot happen in our setting. Instead, some fraction of the Northern firms opts to establish a subsidiary in the opposite country of the North, while the remaining firms continue to export. The total number of firms and the fraction in each category adjust so that $x_{H}^{s}=\left(1-\lambda_{H}\right) d_{H}^{\mathcal{R}}$ despite the changes in $h_{H}$. As $h_{H}$ continues to decline, the fraction of Northern firms that chooses to serve the other market in the North with subsidiary sales grows, until all such Northern firms operate in this manner. Thereafter, it is no longer possible for the market potentials to adjust so as to keep the Northern firms in a state of indifference. The equilibrium eventually has $x_{H}^{s}<\left(1-\lambda_{H}\right) d_{H}^{\mathcal{R}}$, with all Northern firms operating as regional multinationals, as represented by a point along $A B$ in Figure 3. ${ }^{11}$

Still further declines in the fixed cost of FDI will bring us to a situation like that depicted in Figure 4. Suppose the equilibrium for high-quality goods ends up on a segment such as $B D$ in that figure. Note that in the limit, as $h_{H}$ approaches zero, such an outcome is inevitable. When

\footnotetext{
${ }^{11}$ In the above considered case, in which North manufactures high-quality products and South manufactures lowquality products, $x_{H}^{s}=\left(1-\lambda_{H}\right) d_{H}^{\mathcal{R}}$ and the break even conditions (7) imply $x_{H}=\left(1+\lambda_{H}\right) d_{H}^{\mathcal{R}}+2 \lambda_{H} d_{H}^{\mathcal{P}}$ and $x_{L}=\left(1+\lambda_{L}\right) d_{L}^{\mathcal{P}}+2 \lambda_{L} d_{L}^{\mathcal{R}}$. Moreover, in this case $\tilde{n}_{L}^{\mathcal{R}}=2 \lambda_{L} n_{L}^{d, \mathcal{P}}, \tilde{n}_{L}^{\mathcal{P}}=\left(1+\lambda_{L}\right) n_{L}^{d, \mathcal{P}}, \tilde{n}_{H}^{\mathcal{P}}=2 \lambda_{H} n_{H}^{d, \mathcal{R}}, \tilde{n}_{H}^{\mathcal{R}}=$ $\left(1+\lambda_{H}\right) n_{H}^{d, \mathcal{R}}+\left(1-\lambda_{H}\right) n_{H}^{s, \mathcal{R}}$. Substituting these values of $\tilde{n}_{q}^{k}$ into the values of $d_{q}^{k}$ in the previous three equations, using (4), we obtain three equations that provide solutions to $n_{H}^{d, \mathcal{R}}, n_{H}^{s, \mathcal{R}}$ and $n_{L}^{d, \mathcal{P}}$. Falling values of $h_{H}$ are reflected in falling values of $x_{H}^{s}$, and we can use these equations to trace the impact of changes in $x_{H}^{s}$ on $n_{H}^{d, \mathcal{R}}, n_{H}^{s, \mathcal{R}}$ and $n_{L}^{d, \mathcal{P}}$. Recall that rising values of $n_{H}^{s, \mathcal{R}}$ represent FDI by more Northern firms.
} 
the equilibrium falls along the segment $B D$, every firm producing some variety of a high-quality product strictly prefers to serve all of its foreign markets via FDI; i.e., all producers of high-quality goods operate as global multinationals. In such circumstances, the break-even condition for an active producer becomes

$$
2 d_{H}^{\mathcal{R}}+2 d_{H}^{\mathcal{P}}=x_{H}+3 x_{H}^{s}
$$

irrespective of whether a firm is headquartered in the North or the South. Then, the distribution of firms across countries is not determined, although the total number of producers is unique.

We have described the possible outcomes that arise for different relative costs of FDI $h_{H} / f_{H}$ when trade costs and income distributions are such that the trade-only equilibrium has production of high-quality goods only in the North and production of low-quality goods only in the South. Using similar reasoning, we can also identify the equilibria that arise for different relative costs of FDI when the production of both quality levels is globally diversified in the trade-only equilibrium, i.e. when shipping costs are large or regional differences in income distributions are small. In such circumstances, we know from (10) and (11) that $d_{H}^{k}=x_{H} /(1+3 \lambda)$ for $k=R, P$ in the equilibrium with prohibitive costs of FDI. As before, let us reduce $h_{H}$ while holding $h_{L}$ at a prohibitive level. Naturally, the trade-only equilibrium with diversified production remains in place as long as $h_{H}$ is above the largest $h_{H}$ such that $x_{H}^{s}=\left(1-\lambda_{H}\right) d_{H}^{k}$. At that exact point, we have that producers of high-quality goods are indifferent between all four organizational forms, including the possibility of cross-regional multinationals. For values of $h_{H}$ below that threshold, the market for high-quality goods must be characterized by what we have termed a low relative cost of FDI. Then, we may have either global multinationals producing high-quality goods or regional multinationals operating only in the North. When the trade-only equilibrium displays globally diversified production, even "high" relative costs of FDI turn out to be prohibitive.

In sum, we have established

Proposition 2 Let $\tilde{d}_{H}^{k}$ for $k=\mathcal{R}, \mathcal{P}$ denote the market potentials in the trade-only equilibrium that arises when both $h_{H}$ and $h_{L}$ are prohibitive and suppose that $h_{L} / f_{L}>\left(1-\lambda_{L}\right) /\left(1+\lambda_{L}\right)$. Then, the equilibrium in the high-quality segment has only exporters if $x_{H}^{s}>\left(1-\lambda_{H}\right) \tilde{d}_{H}^{\mathcal{R}}$. If the trade-only equilibrium has specialized regional production in both quality segments, then regional multinationals operate in the North whenever $\left(1-\lambda_{H}\right) \tilde{d}_{H}^{\mathcal{R}}>x_{H}^{s}>\bar{x}_{H}^{s}$ for some $\bar{x}_{H}^{s}>$ $\left(1-\lambda_{H}\right) x_{H} /\left(1+3 \lambda_{H}\right)$. Global multinationals operate for $x_{H}^{s}$ sufficiently close to zero. If the trade-only equilibrium instead has globally diversified production of both goods, then FDI occurs only if $x_{H}^{s}<\left(1-\lambda_{H}\right) x_{H} /\left(1+3 \lambda_{H}\right)$.

This proposition reflects the interplay between the relative fixed cost of FDI and differences in income distribution between regions. When income distributions are more similar across regions (so that the trade-only equilibrium features incomplete specialization), multinationals are less likely to emerge. When income distributions are sufficiently different, regional multinationals operate in the North for relative costs $h_{H} / f_{H}$ that could not give rise to multinational investment were the income distributions more similar. 
Of course, the same reasoning applies to reductions in $h_{L}$ from an initially prohibitive level when the fixed cost of FDI in the high-quality segment remains prohibitive throughout. Then, if the trade-only equilibrium features complete regional specialization in both quality segments, regional multinationals will appear in the South, first as a fraction of all Southern firms and eventually as a dominant means for Southern firms to serve their other, large market. When $h_{H}$ and $h_{L}$ are both sufficiently small, the equilibrium can be one in which all firms operate as regional multinationals, serving their larger foreign market (in the same region) from a foreign subsidiary, while exporting to the smaller markets in the opposite regions.

In the remainder of this section, let us be a little more precise about the formal conditions under which the various types of equilibria can arise. Suppose we conjecture that the equilibrium has global multinationals in both market segments. As we have just noted, such multinationals - when

they exist - can operate from any home country. We can use (4) for $d_{q}^{k}$ to express the break-even condition for a global multinational as

$$
\sum_{k=\mathcal{R}, \mathcal{P}} \frac{1}{\bar{n}_{q}} \mathbb{E}^{k}\left[\frac{\left(\bar{n}_{q}\right)^{\theta_{q}} \phi_{q}(y)}{\left(\bar{n}_{H}\right)^{\theta_{H}} \phi_{H}(y)+\left(\bar{n}_{L}\right)^{\theta_{L}} \phi_{L}(y)}\right]=\frac{1}{2 N}\left(x_{q}+3 x_{q}^{s}\right) \quad \text { for } q=L, H
$$

where $\bar{n}_{q}$ is the total number of products of quality $q$ available in every market. The arguments from Fajgelbaum et al. (2010) establish that these two equations have a unique solution for $\bar{n}_{L}$ and $\bar{n}_{H}$, which has $\bar{n}_{L}>0$ and $\bar{n}_{H}>0$. But the solution for $\bar{n}_{L}$ and $\bar{n}_{H}$ may not be consistent with an equilibrium on the segment $B D$ in both the market for low-quality and high-quality products, as we have just conjectured. In fact, this requires that demands and income distributions be such that

$$
\frac{x_{q}^{s}}{1-\lambda_{q}} \leq d_{q}^{k} \text { for } k=\mathcal{R}, \mathcal{P},
$$

as well as the condition for low costs of FDI introduced in Section 4. If the parameters and market potentials do not fall in these ranges, then our conjecture that an equilibrium exists with global multinationals cannot be justified.

Similarly, we can search for an equilibrium with concentrated production of high-quality goods in the North and concentrated production of low-quality goods in the South, and with regional multinationals operating in both places. We can use (4) to write the break-even conditions for the active producers as

$$
\begin{aligned}
& \frac{1}{\bar{n}_{H}} \mathbb{E}^{\mathcal{R}}\left[\frac{\left(\bar{n}_{H}\right)^{\theta_{H}} \phi_{q}(y)}{\left(\bar{n}_{H}\right)^{\theta_{H}} \phi_{H}(y)+\left(\lambda_{L} \bar{n}_{L}\right)^{\theta_{L}} \phi_{L}(y)}\right]+\frac{1}{\lambda_{H} \bar{n}_{H}} \mathbb{E}^{\mathcal{P}}\left[\frac{\left(\lambda_{H} \bar{n}_{H}\right)^{\theta_{H}} \phi_{q}(y)}{\left(\lambda_{H} \bar{n}_{H}\right)^{\theta_{H}} \phi_{H}(y)+\left(\bar{n}_{L}\right)^{\theta_{L}} \phi_{L}(y)}\right] \\
& =\frac{1}{2 N}\left(x_{H}+x_{H}^{s}\right)
\end{aligned}
$$


and

$$
\begin{aligned}
& \frac{1}{\lambda_{L} \bar{n}_{L}} \mathbb{E}^{\mathcal{R}}\left[\frac{\left(\lambda_{L} \bar{n}_{L}\right)^{\theta_{L}} \phi_{q}(y)}{\left(\bar{n}_{H}\right)^{\theta_{H}} \phi_{H}(y)+\left(\lambda_{L} \bar{n}_{L}\right)^{\theta_{L}} \phi_{L}(y)}\right]+\frac{1}{\bar{n}_{L}} \mathbb{E}^{\mathcal{P}}\left[\frac{\left(\bar{n}_{L}\right)^{\theta_{L}} \phi_{q}(y)}{\left(\lambda_{H} \bar{n}_{H}\right)^{\theta_{H}} \phi_{H}(y)+\left(\bar{n}_{L}\right)^{\theta_{L}} \phi_{L}(y)}\right] \\
& =\frac{1}{2 N}\left(x_{L}+x_{L}^{s}\right),
\end{aligned}
$$

where, as before, $\bar{n}_{q}$ is the total number of varieties with quality $q$ produced in the world economy. Here, the distribution of production of the high-quality goods across the two Northern countries is not determined, nor is the distribution of production of low-quality goods across the two Southern countries. The solution to this pair of equations characterizes an equilibrium provided that the implied market potentials are consistent with the assume behavior of firms, i.e., that

$$
d_{L}^{\mathcal{R}} \leq \frac{x_{L}^{S}}{1-\lambda_{L}} \text { and } d_{H}^{\mathcal{P}} \leq \frac{x_{H}^{S}}{1-\lambda_{H}}
$$

and

$$
d_{L}^{\mathcal{P}}>\frac{x_{L}^{s}}{1-\lambda_{L}} \text { and } d_{H}^{\mathcal{R}}>\frac{x_{H}^{s}}{1-\lambda_{H}},
$$

where (14) ensures that firms prefer to export to the markets in the opposite region than to establish subsidiaries there and (15) ensures that firms prefer to operate as regional multinationals than as exporters or as global multinationals. In addition, we need the condition for high costs of FDI introduced in Section 4.

The discussion in this section points to two broad conclusions. First, we see that home-market effects tend to drive the production of high-quality goods to the North and the production of low-quality goods to the South. These patterns of specialization can be partial or complete. Our analysis in Fajgelbaum et al. (2011) established such predictions in a world with trade as the only vehicle for foreign sales, but we see now that they apply as well when multinational investment is possible. The costliness of trade and FDI give an advantage to firms that enjoy a large home market. Once biased entry occurs, these firms will serve (some or all) foreign markets with exports when transport costs are small relative to the costs of establishing foreign subsidiaries and will serve these markets with subsidiary sales when the opposite is true.

Second, we find that the proximity-concentration tradeoff biases the pattern of delivery toward a preponderance of within-region FDI compared to cross-region FDI. Firms opt for subsidiaries over exports when serving larger markets. If demands patterns are more similar within regions than across regions, then having a large market at home tends to go hand in hand with having a large market in other countries at a similar level of development. These forces imply that regional multinationals are more likely to arise when differences in per capita income between regions are large and the relative cost of FDI lies in some intermediate range. When the two regions have sufficiently similar income distributions, global multinationals dominate regional FDI.

Since our model features trade and FDI in final consumer goods, it implies that trade and FDI are substitutes; when a firm chooses to serve a foreign market via subsidiary sales it does not export 


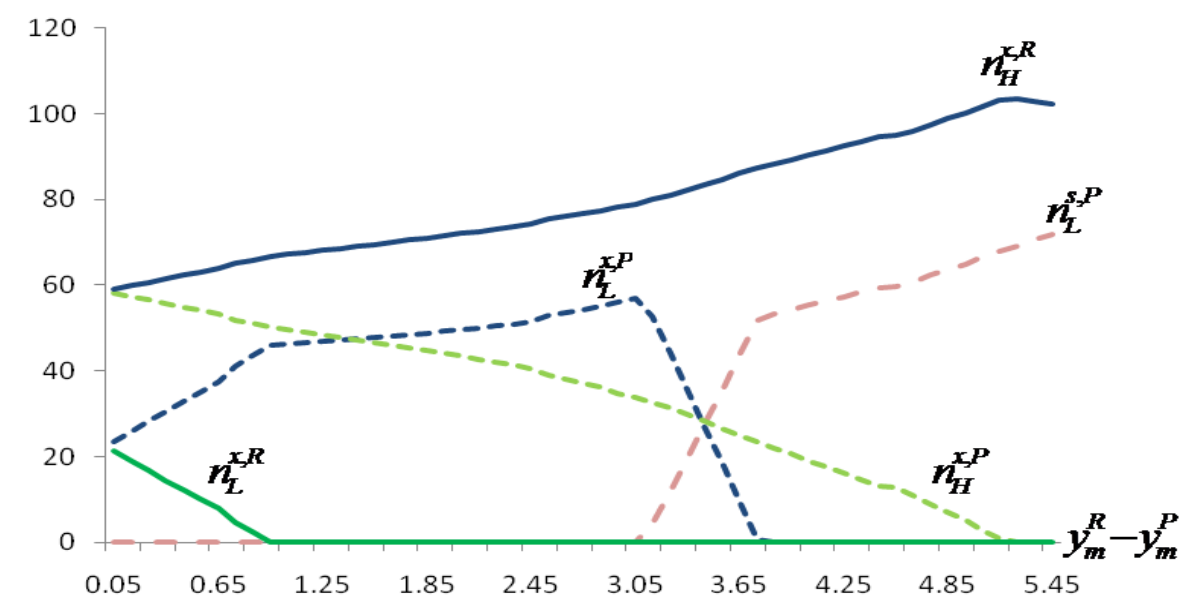

Figure 5: Trade and FDI with high fixed FDI costs

to that market, and when it chooses to export it does not engage in subsidiary sales. Under these circumstances in a sector with large Linder-type FDI there is little Linder-type trade. In order to avoid this feature of the model one can add intermediate inputs to the production of varieties of the differentiated product. When these inputs are quality specific, i.e., high-quality goods require inputs that are not suitable for low-quality goods and vice versa, countries trade in intermediate inputs both in the presence and in the absence of foreign direct investment. As a result, when a firm chooses to serve a foreign market via subsidiary sales this decision substitutes for trade in final goods but it increases trade in intermediate inputs, so that Linder-type trade does not necessarily decline. $^{12}$

\subsection{North-South Income Gaps}

We explore next how differences in per capita income influence the pattern of trade and investment. We begin with a case with high costs of FDI, as in Figure 3, and a negligible difference in income between North and South. As we have shown in Fajgelbaum et al. (2011), a small income gap gives rise to a trade equilibrium with production of low and high quality goods in all countries. The initial equilibrium is at a point such as $C$ in Figure 3 for both the high-quality segment and the low-quality segment. The two Northern countries are net exporters of the high-quality goods to the countries in the South, while the Southern countries are net exporters of the low-quality goods in their trade with the North. Trade between countries in the same region is balanced in each quality segment.

Now let the North-South income gap grow, while keeping aggregate world income constant. The market for high-quality goods expands in the North, while that for low-quality goods expands in the South. At some point, these differences in market size grow sufficiently large that production

\footnotetext{
${ }^{12}$ See, for example, Ramondo and Rodriguez-Clare (2009) who use a model in which only intermediate goods are traded internationally.
} 
of low-quality goods cannot be sustained in the North, nor can production of high-quality goods occur in the South. With specialization by region, the equilibrium in the high-quality segment occurs at a point along $B C$ in Figure 3, whereas that for the low-quality segment occurs along $C D$. A still greater widening of the income gap can make FDI attractive for regional sales. For example, the equilibrium in the market for low-quality goods can reach a point such as $D$, where Southern firms are indifferent between serving the other Southern market with exports or from a foreign subsidiary. Finally, for a sufficiently large income gap, the equilibrium can have all firms in one or both quality segments operating as regional multinationals.

Figure 5 plots the numbers of varieties at each quality level produced in a typical Northern country and in a typical Southern country as functions of the difference in mean income between the two regions for a parameterized example. In this example, the relative cost of FDI is high in the low-quality segment, but prohibitive in the high-quality segment. In generating the figure, we have assumed that income in each country is distributed according to a Gamma distribution with mean $y_{m}^{\mathcal{R}}$ in the North and $y_{m}^{\mathcal{P}}$ in the South. The difference in mean incomes is plotted along the horizontal axis, with the aggregate world income held constant throughout. The lines labeled $n_{q}^{x, k}$ represents the number of firms entering in quality segment $q$ in one of the countries of region $k$, all of which are exporters. For high-quality goods we have $n_{H}^{d, k}=n_{H}^{x, k}$ for $k=\mathcal{R}, \mathcal{P}$. For low-quality goods we have $n_{L}^{d, \mathcal{R}}=n_{L}^{x, \mathcal{R}}$ in North, where no low-quality products are produced by multinationals, and $n_{L}^{d, \mathcal{P}}=n_{L}^{x, \mathcal{P}}+n_{L}^{s, \mathcal{P}}$, where $n_{L}^{x, \mathcal{P}}$ represents the number of firms that operate as exporters of low-quality goods in the typical Southern country while $n_{L}^{s, \mathcal{P}}$ is the number of regional multinationals with foreign subsidiaries producing low-quality goods in the South. ${ }^{13}$

The figure shows that all countries produce in both quality segments when the income gap is small. Also, for small differences in mean income, all markets are served by exports. In this example, producers of high-quality goods do not operate foreign subsidiaries for any of the mean income differences shown in the figure. As the income gap widens, the number of high-quality brands produced in the North rises, while that in the South falls, until the latter eventually declines to zero. For a large enough difference in mean income, the home-market advantage of the North in high-quality products spells an end to production in the South.

A widening of the income gap also leads to greater specialization in the market for low-quality goods. As the gap grows, the size of the market for low-quality products grows in the South and shrinks in the North. Correspondingly, the number of low-quality products produced by Southern firms expands and the number of such products produced by Northern firms shrinks. Once production of low-quality disappears in the North, further increases in the income gap eventually generate a change in the mode of delivery by Southern firms. Regional multinationals spring into existence in the South and initially coexist with Southern firms that operate solely as exporters. There is a range of income differences for which regional multinationals and exporters coexist in the market for low-quality goods, corresponding to an equilibrium at point $D$ in Figure 3 . When the income

\footnotetext{
${ }^{13}$ The parameters used to generate the figure are $f_{L}=1.5, f_{H}=5, c_{L}=0.05, c_{H}=0.3, q_{L}=0.9, q_{H}=1.05$, $\theta_{L}=0.5, \theta_{H}=0.7, x_{L}^{s} / x_{L}=1 / 5, x_{H}^{s} / x_{H}=1, \lambda_{L}=\lambda_{H}=0.55, N=500$, and $y_{m}^{\mathcal{P}}+y_{m}^{\mathcal{R}}=16$.
} 


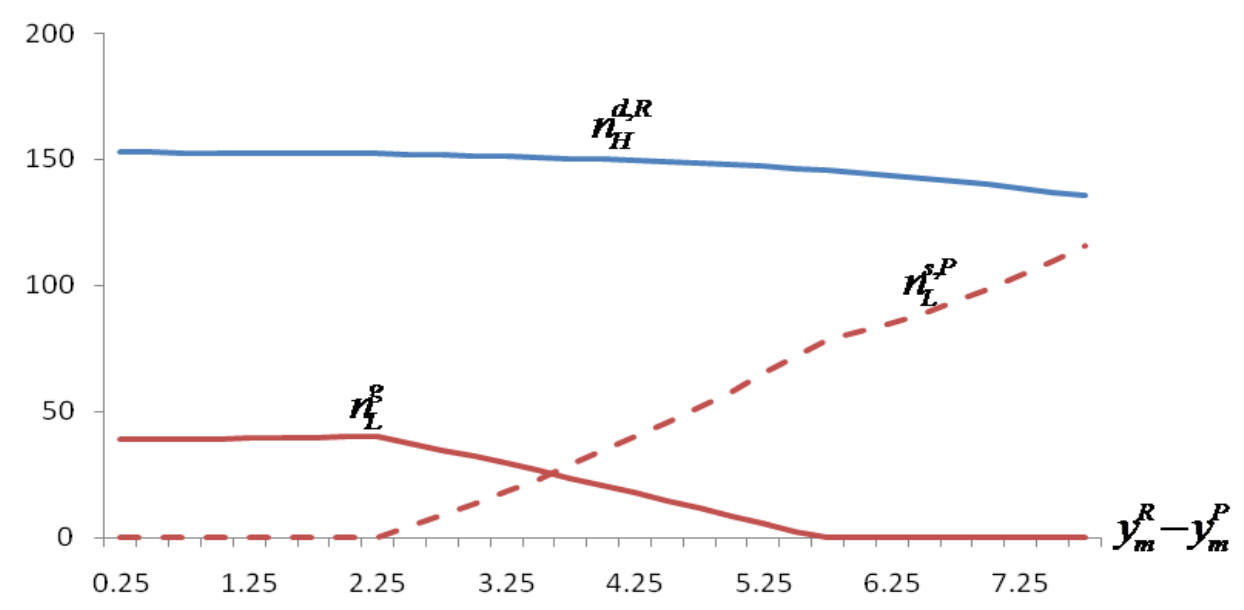

Figure 6: Trade and FDI with low fixed FDI costs

gap grows still larger, the Southern exporters disappear and all firms headquartered there operate as South-to-South multinationals.

Next consider a case with low fixed costs of FDI, such as is depicted in Figure 4. When the North-South income gap is tiny, the markets for a given quality of good are almost the same size in the four countries. The equilibrium features global multinationals that could be headquartered anywhere. Then, as the income gap grows, the equilibrium in the market for high-quality goods moves toward point $B$ in Figure 4, while that in the market for low-quality goods moves toward point $D$. At point $B$, both global multinationals (located anywhere) and regional multinationals in the North earn zero profits producing high-quality goods, so both types of firms can coexist. At point $D$, regional multinationals in the South and global multinationals break even producing low-quality goods. For large enough differences in mean income levels, the high-quality segment has an equilibrium along $A B$, with regional (North-to-North) multinationals operating in the North, and no production in the South. Similarly, the low-quality segment has an equilibrium along $D E$, with regional (South-to-South) multinationals operating in the South, and no production in the North.

Figure 6 depicts a parameterized example of this. ${ }^{14}$ In this example, the relative cost of FDI is low in both quality segments. The example confirms the presence of global multinationals for small and moderate differences in mean incomes. As we have noted previously, the model does not determine where these firms are headquartered, but nor does that outcome matter for any of the aggregate variables. As the difference in mean income grows, the structure of the market for low-quality products evolves. For a moderate income gap, firms in the South are indifferent between serving the North with exports and opening foreign subsidiaries there. There is a determinate number of global multinationals - labeled $n_{L}^{g}$ - that may be located in the North or in the

\footnotetext{
${ }^{14}$ The parameters for this example are $f_{L}=1.5, f_{H}=5, c_{L}=0.05, c_{H}=0.3, q_{L}=0.9, q_{H}=1.05, \theta_{L}=0.5$, $\theta_{H}=0.7, x_{L}^{s} / x_{L}=0.2, x_{H}^{s} / x_{H}=0.2, \lambda_{L}=\lambda_{H}=0.4, N=500$, and $y_{m}^{\mathcal{P}}+y_{m}^{\mathcal{R}}=16$.
} 
South. But the equilibrium has, as well, a determinate number of regional multinationals that must be headquartered in the South; this number is depicted by the dotted curve, $n_{L}^{s, \mathcal{P}}$, where the superscripts indicate that these are regional subsidiaries involving South-to-South FDI. This number expands as the income gap widens, until eventually these regional multinationals replace the global multinationals entirely.

\subsection{Market Size}

In this section, we examine the relationship between overall market size and patterns of trade and FDI. We capture market size in a country by the parameter $N^{k}$, which represents the number of households that purchases a unit of some variety of differentiated product. In general, an increase in market size in a country or region tends to provide absolute advantages across all differentiated goods thanks to the home-market effect. The advantage of rich countries in the high-quality segment grows even larger when the overall size of the market for differentiated products expands relative to that in the South. Moreover, when Northern markets are larger than Southern markets, firms in the North may begin to capture world markets for low-quality goods as well. As before, we are specially concerned with finding conditions for the emergence of regional multinationals. We explore both differences in size between North and South and asymmetries in size between the two countries in a given region.

We begin with the case in which the pair of countries that comprise a region are similar in size, but each country in the North is bigger than its counterpart in the South. We will start from a configuration similar to that in the last section, where market sizes are identical across the four countries but only income distributions differ. From that starting point, we will examine the implications of an increase in market size in the North. Take first the case in which the fixed cost of FDI is high according to our previous taxonomy, so that Figure 3 applies. With reasonably high shipping costs or sufficiently close income distributions, goods of both quality levels are produced in all four countries. The equilibrium is at point $C$ in both quality segments. As $N^{\mathcal{R}}$ increases, the size of the market expands in the North in all quality segments. ${ }^{15}$ The analysis in Fajgelbaum et. al. (2011) indicates that, for a sufficiently large $N^{\mathcal{R}}$, production of all differentiated products migrates to the North. In that case, the equilibrium lies on segment $B C$ of Figure 3 for both quality segments, but multinational investment does not occur. The North produces all differentiated products and the South specializes in the homogenous good.

Further increases in $N^{\mathcal{R}}$ drive the trade-only equilibrium in both quality segments towards point $B$ in Figure 3. Suppose that the equilibrium reaches this point first in the high-quality segment. In such circumstances, the market size in each Northern country is so large that Northern firms are indifferent between serving the other country in the same region via subsidiaries sales or exports. Reasoning as in the previous section, we can infer that for a sufficiently large $N^{\mathcal{R}}$ the equilibrium must lie along segment $A B$. A similar logic applies to low-quality goods. Therefore, for sufficiently large differences in market size between the two regions, regional multinationals emerge in the

\footnotetext{
${ }^{15}$ Note, from the definition of $d_{j}^{k}$ in $(2)$, that $N^{k}$ is part of the market potential in $k$.
} 
larger region, and they might do so in both quality segments. A similar logic applies when we start from a case of low costs of FDI. Under such conditions, when we start from a situation of very similarly-sized countries, we have global multinationals in both quality segments. As $N^{\mathcal{R}}$ grows, demands slide across $B C$ towards the $A B$ segment of Figure 4, whereupon regional multinationals emerge.

In summary, asymmetries in market size between regions drive firms operating in both quality segments toward the larger region. When the difference in size between regions is sufficiently great, regional multinationals emerge in the larger region. The logic underlying this outcome is common to the case of both high and low costs of FDI. As the size of countries in one region increases, there is necessarily entry of new firms in both quality segments. In the case of high costs of FDI, these are exporters who tend to be headquartered in the largest region, while in the case of low cost of FDI they are global multinationals that can be headquartered anywhere in the world. This worldwide increase in the number of firms necessarily increases competition in the region whose market size is not growing, driving down market potentials. When the number of consumers becomes sufficiently large in the expanding region, the size of the market in the other region is too small for firms headquartered there to break even. In the limit, as the number of firms keeps rising, market potentials approximate zero in the region with the fixed population. Since the equilibrium must lie on the contours defined in Figures 2 to 3, regional multinationals must arise if costs of FDI are not prohibitive.

We study next the effects of size differences within a region. Suppose that the two Northern countries are similar in size, while, in the South, country $P_{1}$ has a larger population than country $P_{2}$. The two countries in each region share the same distribution of income. We are interested in examining how the division of population between $P_{1}$ and $P_{2}$ affects the patterns of FDI and trade. To this end, let $N^{\mathcal{P}_{1}}=N+\Delta$ and let $N^{\mathcal{P}_{2}}=N-\Delta$, where $N=N^{\mathcal{R}_{1}}=N^{\mathcal{R}_{2}}$ and $\Delta \geq 0$. This specification makes the two regions equal in size for any value of $\Delta$. We begin from a situation in which, when $\Delta=0$ (so that all countries have the same population size) there is only Northto-North and South-to-South FDI. Northern multinationals specialize in high-quality products and Southern multinationals specialize in low-quality products. For concreteness we focus on the case in which the costs of FDI are high, so that the equilibrium lies on segment $A B$ of Figure 4 for high-quality products, and on segment $D E$ of that figure for low-quality products.

When $\Delta=0$, as we showed in Section 5.1, the equilibrium conditions (12) and (13) determine the total numbers of high-quality and low-quality products, $\bar{n}_{H}$ and $\bar{n}_{L}$, but the numbers of firms with headquarters in each country is not determined. Firms that produce high-quality goods might be based either in $R_{1}$ or $R_{2}$ and firms that produce low-quality goods might be headquartered in either $P_{1}$ or $P_{2}$. In this equilibrium along $A B$ of Figure $4,(14)$ and (15) must be satisfied; that is, the firms in either region find it optimal to export to the opposite, but to serve the other country in their own region with sales from a foreign subsidiary.

Now suppose that $P_{1}$ is slightly larger than $P_{2}$; i.e., $\Delta>0$, but $\Delta$ is small. Inasmuch as the two Southern countries share the same income distribution and the same prices, the movement of a 
representative sample of households from $P_{2}$ to $P_{1}$ has no affect on aggregate demand and therefore no effect on the incentives for firms to enter as producers of low-quality goods in the South or as producers of high-quality goods in the North. A small increase in $\Delta$ from $\Delta=0$ leaves $\bar{n}_{H}$ and $\bar{n}_{L}$ unchanged, and the location of the firms' headquarters in a given region remains indeterminate. ${ }^{16}$ This argument requires, of course, that the asymmetry in population sizes creates no incentive for any firm to alter its mode of serving any market. That is, firms in each region must continue to prefer serving the opposite country in their own region with subsidiary sales and the markets in the opposite region with export sales despite the altered distribution of consumer location. This will indeed be the case provided that

$$
(N+\Delta) d_{H}^{\mathcal{P}}<\frac{x_{H}^{s}}{1-\lambda_{H}}
$$

and

$$
(N-\Delta) d_{L}^{\mathcal{P}}>\frac{x_{L}^{s}}{1-\lambda_{L}}
$$

where $d_{q}^{k}$ is per capita demand for the product with quality $q$ in country $k$ in the equilibrium with equal-sized countries.

But note that a sufficiently large $\Delta$ will cause (16) or (17) to be violated. As country $P_{1}$ grows large and $P_{2}$ small, either firms headquartered in $P_{1}$ will prefer to serve the small market $P_{2}$ with exports, or firms in the North will prefer to serve the large market in $P_{1}$ from a subsidiary located there. Suppose, for example, that $(N+\Delta) d_{H}^{\mathcal{P}}<x_{H}^{s} /\left(1-\lambda_{H}\right)$ but $(N-\Delta) d_{L}^{\mathcal{P}}<x_{L}^{s} /\left(1-\lambda_{L}\right)$. Then Southern firms in $P_{1}$ prefer to export to $P_{2}$ rather than to invest in a subsidiary there, and these firms enjoy a cost advantage by dint of their large home market compared to firms in $P_{2}$. Production of low-quality goods concentrates in the larger of the two Southern markets and firms there export to all foreign markets.

Figure 7 illustrates this in a parametrized example. ${ }^{17}$ The horizontal axis shows the difference in population size between the two countries in the Southern region. The figure shows the number of firms of the various types as a function of $\Delta$. For small enough differences in size, the equilibrium has only regional multinationals. The curve labeled $n_{L}^{s, \mathcal{P}}$ shows the number of these producing low-quality products in the South and that labeled $n_{H}^{s, \mathcal{R}}$ shows the number producing high-quality products in the North. As consumers migrate from $P_{2}$ to $P_{1}$, country $P_{1}$ attains a size that makes it profitable to sell high-quality products from local subsidiaries there. A new type of Northern multinational emerges that has subsidiaries in the other market of the North and in $P_{1}$, but not in $P_{2}$. As $P_{1}$ continues to grow at the expense of $P_{2}$, the number of such multinationals (labeled $\left.m_{H}^{s, \mathcal{R}}\right)$ increases while the number of regional multinationals declines. Eventually, it also becomes

\footnotetext{
${ }^{16}$ This argument requires that the cost of producing a unit of output in a foreign subsidiary literally is the same as at home. If production near to headquarters generates even a tiny cost differential, this would create a home-market advantage for the firms headquartered in country $\mathcal{P}_{1}$ and this country would capture all of the producers of the low-quality good.

${ }^{17}$ The parameters for this example are $f_{L}=1, f_{H}=6, c_{L}=0.05, c_{H}=0.3, q_{L}=0.9, q_{H}=1.05, \theta_{L}=0.6$, $\theta_{H}=0.6, x_{L}^{s} / x_{L}=0.2, x_{H}^{s} / x_{H}=0.2, \lambda_{L}=0.4, \lambda_{H}=0.46, N=500, y_{m}^{\mathcal{P}}=5$ and $y_{m}^{\mathcal{R}}=50$.
} 


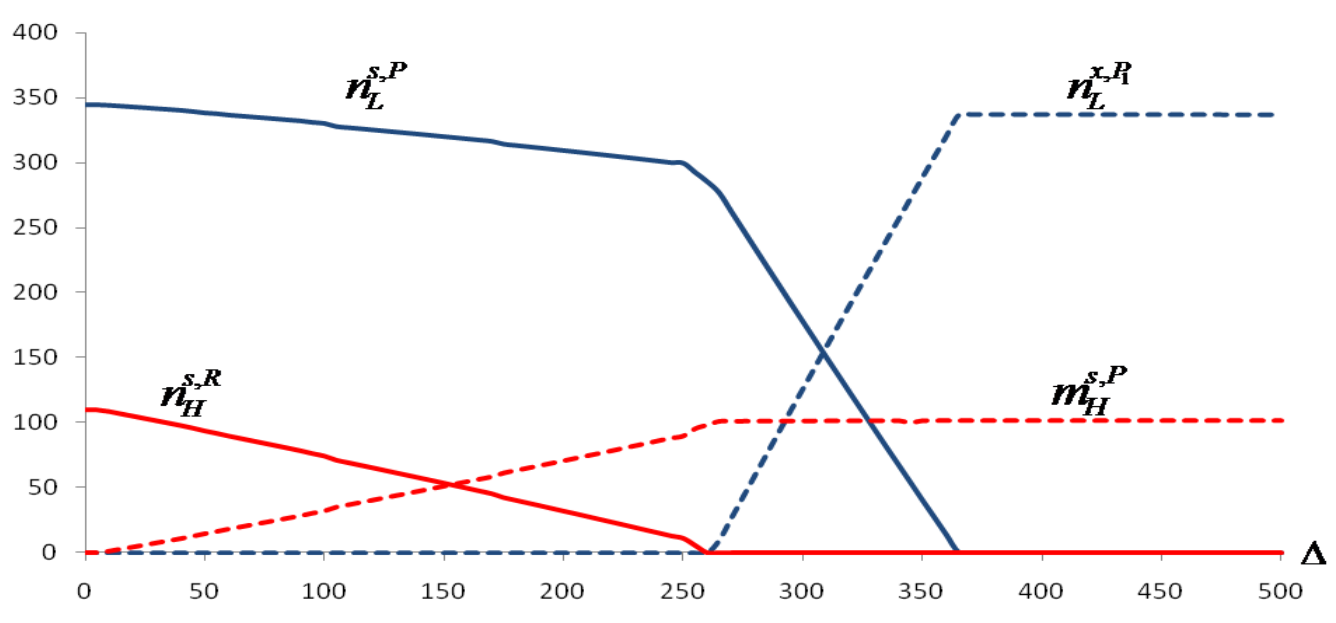

Figure 7: Differences in Market Size

optimal for firms in $P_{2}$ to close their subsidiaries in $P_{1}$ and to instead serve the small market for low-quality products with export sales. The number of firms located in $P_{1}$ that export to all foreign markets is denoted in the figure by $n_{L}^{x, \mathcal{P}_{1}}$. For large enough differences in size between $P_{1}$ and $P_{2}$, there is no FDI by Northern or Southern firms in the latter market.

\section{Conclusion}

In this paper, we have combined a product-quality view of the Linder hypothesis with a proximityconcentration view of firms' decisions about how to serve their foreign markets. We conjectured that non-homothetic preferences and home-market effects, which are known to affect patterns of world trade, should influence patterns of foreign direct investment as well. The tradeoff between proximity and concentration implies that firms are more likely to serve foreign markets from local production facilities when those markets are large. Non-homothetic preferences for vertically differentiated products forge a connection between a country's income level and distribution and the mix of qualities it consumes. Accordingly, country income and product quality are bound to influence firms' choices between foreign investment and international trade. We have extended the model in Fajgelbaum et al. (2011) to allow for affiliate sales by multinational corporations and used the extended model to examine the circumstances under which firms in a country will choose to serve some foreign markets by exports and others by subsidiary sales.

Our analysis establishes a systematic bias in FDI toward countries at a similar stage of development. In a simple setting that allows for both regional and cross-regional FDI, we find that North-North FDI or South-South FDI must occur in any equilibrium that features multinational investment. Moreover, if the income distribution in each Northern country dominates that in each Southern country, multinationals from the North specialize in producing high-quality products while multinationals from the South specialize in producing low-quality products. For given fixed 
costs of FDI, regional multinationals are more likely to arise the more disparate are the income distributions of the two regions. In keeping with the empirical evidence, the share of foreign affiliate sales in total sales falls with the difference in per capita income between trading partners.

Our analysis provides an explanation for the fact that multinational sales are more responsive to income gaps than export sales, as documented by Brainard (1997) and others. In our model, FDI is more common across countries with similar income levels, because such countries tend to specialize their production of goods of similar quality. Our analysis also suggests a potential contributing factor in the recent surge in South-to-South FDI. For example, we find that the rise in multinational activity that naturally follows from a decline in the cost of establishing foreign subsidiaries has a distinctive pattern: firms first locate foreign subsidiaries in markets that are similar to their home market before choosing to serve very different markets in this manner. Moreover, we find that smaller asymmetries in market size within regions are more conducive to regional FDI. Therefore, the convergence of China and India toward the income levels of other emerging-market countries might also account for part of the recent growth in South-to-South FDI. 


\section{References}

[1] Aykut, Dilek and Ratha, Dilip (2004), "South-South FDI Flows: How Big Are They?," Transnational Corporations 13:1, 149-177.

[2] Bergstrand, Jeffrey H. (1990), "The Heckscher-Ohlin-Samuelson Model, The Linder Hypothesis and the Determinants of Bilateral Intra-Industry Trade," Economic Journal 100:403, 12161229 .

[3] Bils, Mark and Klenow, Peter J. (2001), "Quantifying Quality Growth," American Economic Review 91:4, 1006-1030.

[4] Boston Consulting Group (2006), The New Global Challengers: How 100 Top Companies from the Rapidly Developing Economies are Changing the World, Boston: The Boston Consulting Group.

[5] Brainard, S. Lael (1993), "A Simple Theory of Multinational Corporations and Trade with a Trade-off between Proximity and Concentration," NBER Working Paper 4269.

[6] Brainard, S. Lael (1997), "An Empirical Assessment of the Proximity-Concentration Tradeoff between Multinational Sales and Trade", American Economic Review 87:4, 520-544.

[7] Carr, David L., Markusen, James R. and Maskus, Keith E. (2001), "Estimating the KnowledgeCapital Model of the Multinational Enterprise," American Economic Review 91:3, 693-708.

[8] Dixit, Avinash K. (2011), "International Trade, Foreign Direct Investment, and Security," Annual Review of Economics, 3:1, 191-213.

[9] Fajgelbaum, Pablo, Grossman, Gene M. and Helpman, Elhanan (2011), "Income Distribution, Product Quality, and International Trade," Journal of Political Economy, 118:4, 721-765.

[10] Fieler, Ana Cecilia (2011), "Nonhomotheticity and Bilateral Trade: Evidence and a Quantitative Explanation," Econometrica, 79:4, 1069-1101.

[11] Francois, Joseph F. and Kaplan, Seth (1996), "Aggregate Demand Shifts, Income Distribution, and the Linder Hypothesis," The Review of Economics and Statistics, 78:2, 244-250.

[12] Hallak, Juan Carlos (2006), "Product Quality and the Direction of Trade," Journal of International Economics 68:1, 238-265.

[13] Hallak, Juan Carlos (2010), "A Product-Quality View of the Linder Hypothesis," Review of Economics and Statistics 92:3, 453-466.

[14] Hallak, Juan Carlos and Schott, Peter K. (2011), "Estimating Cross-Country Differences in Product Quality," Quarterly Journal of Economics, 126:1, 417-474. 
[15] Helpman, Elhanan (1984), "A Simple Theory of Trade with Multinational Corporations," Journal of Political Economy 92:3, 451-471.

[16] Helpman, Elhanan, Melitz, Marc and Yeaple, Stephen R. (2004), "Export Versus FDI with Heterogeneous Firms," American Economic Review 94:1, 300-316.

[17] Helpman, Elhanan and Krugman, Paul R. (1985). Market Structure and Foreign Trade, Cambridge, MA: MIT Press (1985).

[18] Horstmann, Ignatius J. and Markusen, James R. (1992), "Endogenous Market Structures in International Trade", Journal of International Economics 32:1-2, 109-129.

[19] Hummels, David and Klenow, Peter J. (2005), “The Variety and Quality of a Nation's Exports," American Economic Review 95:3, 704-723.

[20] Krugman, Paul R. (1980), "Scale Economies, Product Differentiation, and the Pattern of Trade," American Economic Review 70:5, 950-959.

[21] Linder, Staffan Burenstam (1961), An Essay on Trade and Transformation, Stockholm: Almqvist and Wiksell.

[22] Markusen, James R. (1984), "Multinationals, Multi-Plant Economies, and the Gains from Trade," Journal of International Economics 16:3-4, 205-26.

[23] Markusen, James R. (1986), "Explaining the Volume of Trade: An Eclectic Approach," American Economic Review 76:5, 1002-1011.

[24] Markusen, James R. and Maskus, Keith E. (2002), "Discriminating Among Alternative Theories of the Multinational Enterprise," Review of International Economics 10:4, 694-707.

[25] Markusen, James R. and Venables, Anthony J. (2000), "The Theory of Endowment, IntraIndustry, and Multinational Trade," Journal of International Economics 52:2, 209-34.

[26] McFadden, Daniel L. (1978), "Modelling the Choice of Residential Location," in A. Karlvist. L. Lundqvist, F. Snickars and J. Weibull (eds.), Spatial Interaction Theory and Planning Models, Amsterdam: North Holland, 75-96.

[27] Ramondo, Natalia (2011), "A Quantitative Approach to Multinational Production," Arizona State University, manuscript.

[28] Ramondo, Natalia and Rodríguez-Clare, Andrés (2009), "Trade, Multinational Production, and the Gains from Openness," NBER Working Paper 15604.

[29] Schott, Peter K. (2004), "Across-Product versus Within-Product Specialization in International Trade," Quarterly Journal of Economics 119:2, 647-678. 
[30] Thursby, Jerry G. and Thursby, Marie (1989), "Bilateral Trade Flows, the Linder Hypothesis, and Exchange Risk," The Review of Economics and Statistics, 69:3, 488-495.

[31] UNCTAD (2006), World Investment Report 2006, Geneva: United Nations.

[32] Yeaple, Stephen R. (2009), "Firm Heterogeneity and the Structure of U.S. Multinational Activity," Journal of International Economics, 78:2, 206-2015. 